Abhandlungen des kriminalistischen Seminars an der Universität Berlin.

Neue Folge. Fünfter Band. I. Heft.

\title{
Die Kriminalität
}

im Amtsbezirk Heidelberg.

Von

Dr. Franz Dochow.

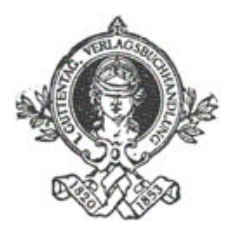

Berlin I906.

J. Guttentag, Verlagsbuchhandlung,

G. m. b. H. 
J. Guttentag, Verlagsbuchhandlung, G. m. b. H. in Berlin.

\section{v. Liszt, \\ Abhandlungen des kriminalistischen Seminars.}

Zwciter Band, Heft I und II.

Der strafrechtliche Schutz des Rechtsguts der Pietät. von Dr. Georg Crusen. Preis $4 \mathrm{M}$.

Welche Strafmittel können an die Stelle der kurzzeitigen Freiheitsstrafe gesetzt werden? Von Dr. Ernst Rosenfeld. Mit großen Tabellen. Preis $6 \mathrm{M}$.

Dritter Band, Heft I-IV.

Der Rückfall. Eine kriminalpolitische und dogmatische Untersuchung. Von J. Sacker. Preis 3 M.

Der strafrechtliche Schutz der Eisenbahnen im Deutschen Reiche. Von Dr. Walter Loock. Preis $3 \mathrm{M}$.

Der sogenannte Futterdiebstahl nach deutschem Recht. Von Arthur Schwarze. Preis 2 M. 50 Pf.

Das Verhältnis zwischen der Defraudation der Zölle und Verbrauchssteuern und dem Betruge nach deutschem Reichsrecht. Von Wilhelm Honemann. Preis I M. 5o Pf.

\section{Vierter Band, Heft I.}

Wasser-Diebstahl. Von Dr. Walther v. Hippel. Preis I M. 50 Pf,

\section{Neue Folge. Band I. Heft $\mathrm{I}-5$.}

Die Straflosigkeit der actio libera in causa. von Dr. Richard Katzenstein. Preis $7 \mathrm{M}$.

Getreidepreise und Kriminalität in Deutschland seit 1882. Von Hermann Berg. Mit 3 Tafeln. Preis I M. 50 Pf.

Die Lehre von der adäquaten Verursachung. Von Dr. Gustav Radbruch. Preis $2 \mathrm{M}$.

Die Stellung der Bufse im reichsrechtlichen System des Immaterialgüterschutzes. Von Dr. Alexander Graf zu Dohna. Prejs 2 M.

Der Begriff des Zuhälters im Reichsstrafgesetzbuch. von Dr. Sally Jaffa. Preis I M. 20 Pf.

Fortsetzung siehe Seite 3 des Umschlags. 



\section{Abhandlungen \\ des \\ kriminalistischen Seminars \\ an der Universität Berlin.}

Herausgegeben

von

Dr. Franz v. Liszt,

ord. Professor der Rechte zu Berlin.

Neue Folge. Fünfter Band. r. Heft.

Franz Dochow: Die Kriminalität im Amtsbezirk Heidelberg.

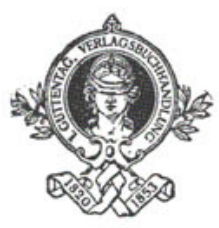

Berlin 1906.

J. Guttentag, Verlagsbuchhandlung, G. m. b. H. 


\section{Die Kriminalität}

im Amtsbezirk Heidelberg.

Von

Dr. Franz Dochow.

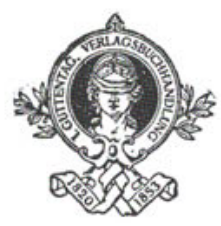

Berlin 1906.

J. Guttentag, Verlagsbuchhandlung,

G. m. b. H. 

Sr. Exzellenz

\title{
dem Herrn Staatsminister
}

\section{Dr. HANS FREIHERRN VON BERLEPSCH}

\author{
in dankbarer Verehrung
}

überreicht

vom Verfasser. 
